\title{
The water deficit and aridity indexes in the Capitanata plain calculated by statistical downscaling
}

\author{
Luigi Palatella, ${ }^{1}$ Domenico Vitale, ${ }^{2}$ Domenico Ventrella, ${ }^{2}$ Gianfranco Rana ${ }^{2}$ \\ ${ }^{1}$ CNSIM, Consorzio Nazionale Interuniversitario per le Scienze Fisiche della Materia - UdR di Lecce; \\ Dipartimento di Ingegneria dell'Innovazione, Università del Salento, Lecce; ${ }^{2}$ Consiglio per la \\ Ricerca e la sperimentazione in Agricoltura, Unità di ricerca per i Sistemi Colturali degli Ambienti \\ caldo-aridi (CRA-SCA), Bari, Italy
}

\begin{abstract}
This work describes the results obtained by the statistical downscaling technique for the assessment of changes in precipitation (P), potential evaporation (PE). In turn $\mathrm{P}$ and $\mathrm{PE}$ are used for computing two indexes of water availability, namely the index of water deficit (WDI) and the aridity index (AI). The analysis is carried out for the Capitanata plain (South-East of Italy) and the A2 scenario of the IPCC Assessment Report 4 (AR4). The large-scale temperature at the $1000 \mathrm{hPa}$ level and sea level pressure fields are used as predictors. The local precipitation and potential evaporation time series are used as predictands. The statistical downscaling technique used is based on Canonical Correlation Analysis. A validation procedure of the model is performed and the same technique is used for climatic projections of $\mathrm{P}, \mathrm{PE}$ and consequently WDI and AI. Climate analysis and projections at this local space scale is an important issue not only for current water management and planning, but also for improving the irrigation efficiency considering future climate change scenarios.
\end{abstract}

Correspondence: Luigi Palatella, Dipartimento di Ingegneria dell'Innovazione, Università del Salento, Str. Prov. Lecce-Arnesano, 73100 Lecce, Italy. E-mail: luigi.palatella@yahoo.it

Key words: climate change, impacts assessment, precipitation, potential evaporation.

Acknowledgements: this research was funded by CLIMESCO Evolution of cropping systems as affected by climate change project, contract n. 285, 20/02/2006 (Ministry for Education, University and Research).

Received for publication: 9 March 2011.

Accepted for publication: 8 November 2011.

(C) Copyright L. Palatella et al., 2012

Licensee PAGEPress, Italy

Italian Journal of Agronomy 2012; 7:e3

doi:10.4081/ija.2012.e3

This article is distributed under the terms of the Creative Commons Attribution Noncommercial License (by-nc 3.0) which permits any noncommercial use, distribution, and reproduction in any medium, provided the original author(s) and source are credited.

\section{Introduction}

The potential evaporation (PE) was recently demonstrated to be the right variable for taking into account the atmospheric evaporation demand in a given site (Katerji and Rana, 2011). It was defined (Penman, 1948; Monteith, 1965; Katerji and Rana, 2011) as the evaporation from a surface saturated in water (free water at the surface, or water under dew form above the crop leaves). Afterwards, the potential evapotranspiration concept (PET) was introduced to take into account the biological control (stomatal closure) and the control exerted by the vegetation structure (architecture) on the natural surfaces water losses. The PE is only a theoretical variable because it does not occur in natural conditions, except in the very improbable case in which the plant leaves represent a very thin layer at the top of the stem. However, it assumes a strong fundamental role when it is necessary to study the water requirements of crops at seasonal scale, mainly in the framework of climate change. In fact, the difference between PE and precipitation (P) at monthly-seasonal scale, here called water deficit index (WDI), can be used to design irrigation systems at regional scale (e.g. Davis, 1970) and to develop soil water balance models (Deardoff, 1977; Zhang et al., 1999). Furthermore, WDI well depict the evolution of a climate with respect to water resources at regional scale (Gao and Giorgi, 2008). More often, potential evaporation and precipitation, both calculated at annual time scale, are used to determine the aridity index (AI) as ratio between P and PE (Budyko, 1974; UNEP, 1992). This last index was for a long time used to evaluate the water balance at regional scale (e.g. Oldekop, 1911) and more recently it is also adopted by the UNCCD (UN, 1994) to define arid, semiarid and dry sub-humid areas (e.g. Tsakiri and Vangelis, 2005). Thus, the AI evolution in time gives information about the trend of aridity risk under climate change dynamics.

In the recent past the effect of higher air temperature, change in precipitation patterns and $\mathrm{CO}_{2}$ air concentration increase on the biosphere due to climate change were studied mainly at the large spatial scale of General Circulation Model (GCM). Thus, inevitably, only general conclusions can be drawn about the water budget in agricultural and forest systems (Neilson, 1995; Gerten et al., 2004). Therefore, although the spatial resolution of the GCM is continuously being increased, downscaling procedure of atmospheric information from the large scale to regional and local scales is still needed. Furthermore, the water deficit plays a crucial role when crops grow in semi-arid Mediterranean climatic areas: in such environments, the heterogeneity of the lands and of the cultivated crops imposes an accurate analysis at local space scale (Budyko, 1974).

In general, the techniques used to connect atmospheric information/variables from large to local scale (which are more useful to study 
biophysical processes) are the dynamical and statistical downscaling. In the first approach a regional scale climatic model is run under the boundary condition given by the GCM. Thus a simulation of the meteorological variables is obtained on the scale of the grid of the regional model and it can be as low as few tens of kilometres. Statistical downscaling, instead, is based on the set up of a statistical model, connecting large and small scale variables. This model is made up using long historical records and then used on the projection of large scale variables given by GCM to obtain values of small scale variables. Even if statistical downscaling is not directly based on the physical mechanism governing the climate dynamics, it can be a valid alternative to dynamical downscaling for two main reasons. First of all, the numerical effort to perform statistical downscaling is very low and practically every personal computer has enough computational power to perform a good analysis. Secondly, statistical downscaling can, in principle, describe also very small scale dynamical features, with the condition that they persist along the whole historical records used to calibrate the statistical model, as it happens for orographic and land use effect on climate.

In this paper we follow a partially new approach assessing the statistical downscaling method for P and PE and, then, we calculated WDI and $\mathrm{AI}$, with an outline about the expected future projections. The Capitanata plain was selected as the study area because of its importance in the Italian agriculture context and its representativeness of the Mediterranean environmental condition. The plain is located in the South-East of Italy. This area is characterized by a land use mainly based on agriculture activity and specifically for the cultivation of durum wheat, tomato, sugar beet and vineyard. According to climatic classification, the plain results under Mediterranean semi-arid climate (Aguado et al., 2010).

\section{Materials and methods}

Statistical downscaling involves developing quantitative relationships between large-scale atmospheric variables (predictors) and local surface variables (predictands). Predictor sets are typically sea level pressure, geo-potential height, wind field, absolute or relative humidity and temperature fields. These variables are archived at the grid resolution of global climate models. In statistical downscaling most work has focused on precipitation because it is the most important input variable for many natural systems models (Wilby et al., 2004). Once the relationships between predictors and predictands have been established, then the statistical downscaling based on the climatic projection (scenario) from Global Climate Model (GCM) can be use for producing climatic projections of the local variables. In this work sea level pressure (SLP) and temperature at $1000 \mathrm{hPa}(\mathrm{T})$ were used as predictors. The SLP series was extracted from the EMULATE dataset (Ansell et al., 2006) and it is based on daily averaged sea level pressure values from January 1850 to December 2003. The data cover the region from 70W-70N (top left corner) to $50 \mathrm{E}-25 \mathrm{~N}$ (bottom right corner). The grid is $5 \times 5$ in latitude and longitude. Thus at each time step the dataset is made up of 250 values of SLP. Regarding T, daily re-analysis data were downloaded from the NCEP Reanalysis data (Data provided by the NOAA-ESRL Physical Sciences Division, Boulder Colorado from their Web site at $h t t p / / / w w w . e s r l . n o a a$. gov/psd). These data cover the EuroAsiatic region from $0 \mathrm{~N}$ to $90 \mathrm{~N}$ of latitude and from $90 \mathrm{~W}$ to $90 \mathrm{E}$ of longitude. The grid is $73 \times 37$ with a spatial scale of $2.5 \times 2.5$ degrees. Data cover the period from 1948 to 2007 . Concerning predictands, the monthly precipitation (P) and potential evaporation (PE) time series were used. $\mathrm{P}$ time series collected by the Italian National Hydrographical Service were used to calibrate the statistical model: the analyses were based on six climate time series from stations located in the Capitanata plain and covering the period from 1935 to 2006. PE can be thought as the evaporation from a free water at the surface, or $100 \%$ of humidity at a natural surface. Actually, the surfaces corresponding to the PE definition are the large surfaces of water (lakes, seas, oceans) or very moisten soils. The values of PE (mm/day) can be calculated by the Penman model (Penman, 1948):

$$
P E=\frac{1}{\lambda} \frac{\Delta A+\rho c_{p} D / r_{a}}{\Delta+\gamma}
$$

where $\lambda$ is the latent heat of vaporisation for water $(2.46 \mathrm{MJ} / \mathrm{kg}), \Delta$ is the slope of the saturation vapour pressure function vs. temperature $\left(\mathrm{Pa} /{ }^{\circ} \mathrm{C}\right), \gamma$ is the psychrometric constant $\left(\mathrm{Pa} /{ }^{\circ} \mathrm{C}\right), \rho$ is the density of the air $\left(\mathrm{kg} / \mathrm{m}^{3}\right), c_{p}$ is the specific heat at constant pressure $\left(\mathrm{J} / \mathrm{kg}^{\circ} \mathrm{C}\right), \mathrm{A}$ is the available energy $\left(\mathrm{W} / \mathrm{m}^{2}\right)$ calculated as difference between net radiation and surface heat flux and $r_{a}$ is the aerodynamic resistance $(\mathrm{s} / \mathrm{m})$. The aerodynamic resistance $r$ is the only resistance term in PE: it describes the effect of obstacles encountered by the water vapour passing from the evaporative surface to the reference height $z$. This resistance, which depends on the surface roughness $\left(z_{0}\right)$ and crop height $\left(h_{c}\right)$, is given by the following relation (Perrier, 1975a,b,c,):

$$
r_{a}=\frac{\ln \frac{z-d}{z_{0}} \ln \frac{z-d}{h_{c}-d}}{k^{2} u(z)}
$$

where $d$ is the zero plane displacement height (m), $k$ the von Kármán constant and $u$ is the wind speed $(\mathrm{m} / \mathrm{s})$. The daily time series involved in the computation of the PE were from the agro-meteorological measurements (maximum and minimum temperature, humidity, global radiation and wind speed) collected at the site of Podere 124, an experimental farm of the CRA-SCA located near to Foggia in South Italy $\left(41^{\circ} 26^{\prime} 49^{\prime \prime} \mathrm{N}\right.$, $15^{\circ} 30^{\prime} 15^{\prime \prime} \mathrm{E}, 90 \mathrm{~m}$ a.s.l.). The time series cover the period from 1951 up to 2006. In order to compute the statistical downscaling on a monthly time scale, averaged values were calculated and taken into account in further analyses. We retrieve from the IPCC-Data server (available at http:/www.mad.zmaw.de/em/IPCC_DDC/htmVddc_ gcmdata.html) the SLP and T at $1000 \mathrm{hPa}$ projections relative to the A2 scenario and the Control Run (CTR) of the Assessment Report 4 (AR4) for the GCM ECHAM5/MPI GCM run (Roeckner, 2005). The A2 scenario covers the years from 2010 to 2100, while the CTR regards the period 1961-1990 and is obtained with the atmospheric greenhouse gas concentration observed in the same period. Monthly data are on a grid with $192 \times 96$ points with a resolution of about 1.875 degrees. GCM projections have been interpolated on the same grid of the predictor data in order to project them on the canonical patterns obtained from the statistical model. The climate change signal is computed as the difference between the $\mathrm{A} 2$ and the CTR downscaled values. The agreement between CTR and observed data is a measure of the correspondence between real climate observed in the past and the climate described by the GCM. In this work we used a statistical technique called Canonical Correlation Analysis (CCA). This procedure is well known and we do not describe it here. The interested reader can find very nice reviews of this topic on (von Storch et al., 1993) or on (von Storch and Zwiers, 1999; Zorita and von Storch; 1999). The technical details of the implementation can be found in Palatella et al. (2010). In order to evaluate the reliability of the statistical downscaling procedure the following strategy was adopted. The predictor and predictand climate variables were splitted into two sub-periods, the first was considered as the training/calibration period and the second as the validation/prediction one. The comparison between the observed predictand (i.e. the sub-period not used in the calibration of the model) and downscaled series corresponding to the validation/prediction period provides an evaluation of 
accuracy of the statistical downscaling procedure. Several quantities can be used to assess the agreement between the CCA model results and observations. We use two approaches. One approach is based on performing the Pearson's correlation analysis between the spatial average of the observed and downscaled predictand defined as

$$
r=\frac{\sum_{t=1}^{N}\left(y_{t}-\bar{y}\right)\left(\tilde{y}_{t}-\overline{\tilde{y}}\right)}{\sqrt{\sum_{t=1}^{N}\left(y_{t}-\bar{y}\right)^{2}} \sqrt{\sum_{t=1}^{N}\left(\tilde{y}_{t}-\overline{\tilde{y}}\right)^{2}}}
$$

where $y_{t, j}$ and $\tilde{y}_{t, j}$ are the values of the observed and computed predictand series at time $t$ at station $j$, respectively, $m$ is the number of observations (stations) for each time step, $\mathrm{N}$ is the number of time steps. Barred variables refer to spatial- and time-averaged quantities. We propose another measurement of the model performance evaluating the mean percentage error of the prediction defined as

$$
e_{P}=\frac{\sigma}{p}
$$

where

$$
\sigma^{2}=\frac{1}{N} \sum_{t=1}^{N}\left(\tilde{y}_{t}-y_{t}\right)^{2} \text { and } p=\frac{1}{N} \sum_{t=1}^{N} y_{t}
$$

Notice that $\sigma^{2}$ is referred to as the mean squared error as discussed in (von Storch and Zwiers, 1999, p. 396). This approach can be considered as suitable for strongly not-Gaussian asymmetrically distributed variables, like precipitation. However, for variables having approximately Gaussian distribution, the mean percentage error can be normalized dividing $\sigma$ by the standard deviation (SD) values, i.e.

$$
e_{P E}=\frac{\sigma}{S D}
$$

For PE we also use this approach. Other applications (i.a. Palatella et al., 2010 and reference therein) suggest that the results of this downscaling approach are reasonably accurate at time scale of 5 and 10 -years. The WDI was obtained by subtracting the downscaled values of $P$ from that of $P E$

$$
\mathrm{WDI}=\mathrm{PE}-\mathrm{P} \quad(5 \mathrm{a})
$$

instead, the AI was estimated by dividing downscaled values of $\mathrm{P}$ from that of PE

$$
\mathrm{AI}=\mathrm{P} / \mathrm{PE} \quad(5 \mathrm{~b})
$$

Regarding the $\mathrm{AI}$, usually values of $\mathrm{AI} \geq 1,0.65 \leq \mathrm{AI}<1,0.5 \leq \mathrm{AI}<0.65$, $0.20 \leq \mathrm{Al}<0.50,0.05 \leq \mathrm{AI}<0.20, \mathrm{Al}<0.05$ identify humid, dry sub-humid, dry land, semi-arid, arid and hyper-arid regimes, respectively (e.g. Gao and Giorgi, 2008).

\section{Results and discussion}

In this section we present the results of the CCA analysis, by discussing the best choice for the predictors for $\mathrm{P}$ and $\mathrm{PE}$, then analysing the resulting patterns of $\mathrm{P}, \mathrm{PE}, \mathrm{WDI}$ and $\mathrm{AI}$ for the $\mathrm{A} 2$ scenario.

In the downscaling procedure for $\mathrm{P}$ the training/calibration period was fixed to 38 years and the validation/prediction period to the last 14 years. Concerning PE, instead, the training/calibration period was fixed to 36 years, while the validation/prediction to the last 20 years. The downscaling procedure for $\mathrm{P}$ based on monthly frequencies did not produce good results (data not shown). The short length of the climate time series and its large variability related to the geographical area (Castrignanò et al., 2010; Vitale et al., 2010) may likely be the cause. In order to improve the downscaling results, we computed the winter (December, January, February; DJF), the spring (March, April, May; MAM), the summer (June, July, August; JJA) and the autumn (September, October, November SON); seasonal values. In this way the training/calibration series has 114 points (38 years $\mathrm{x} 3$ ) while the validation/prediction series has 42 points ( 14 years $\mathrm{x} 3$ ). We carried out the analysis, seasonally aggregating monthly values (for example, a time series looks like 1960 March, 1960 April, 1960 May, 1961 March, ...).

We found that the best predictor for the predictand P is SLP. This result is in agreement with the results by von Storch et al. (1993) and von Storch and Zwiers (1999). Some authors (see for example Hertig and Jacobeit, 2008) found good agreement using other predictors (i.e. geopotential height; but we think that SLP is the best one in the present case, due to the fact that no longer time series of other predictors are available for this region. Furthermore, regarding $P$, the mean percentage error $\left(e_{P}\right)$ assumes higher values, especially during summer season when the percent error reaches the 73\% (Table 1). This is not surprising considering that the precipitation phenomena in Mediterranean region, particularly during summer, are less correlated to large scale circulation; indeed during summer, precipitation is largely due to small scale convective systems (Saaroni and Ziv, 2000). However, referring to the Pearson's coefficients, it would seem to be a good fit. On the other hands, other studies (e.g. Palatella et al., 2010; Lionello et al., 2003; Zorita and von Storch, 1999) showed that this method can be acceptably applied to the analysis of climate change signal. Concerning PE predictand the best predictor resulted to be $T$ at $1000 \mathrm{hPa}$. The mean percentage error between observed and predicted annual values are around $16 \%$, with lower values during spring and summer and higher values during autumn and winter months with a peak of $31 \%$ in December (Table 2). Regarding the ePE $_{\mathrm{PE}}$ error indicator, we observe that the downscaling procedure error is lower than standard deviation only in January, March, April and August. These results are not so good but we should remember that the average value of the predictand in

Table 1. Mean percentage error $\left(e_{P}\right)$ and Pearson's coefficient $(r)$ calculated in the validation/prediction period for precipitation $(P)$ time series. Values of $\mathbf{r}$ in italics are statistically significant at $95 \%$ of confidence level.

\begin{tabular}{lllll} 
& DJF & MAM & JJA & SON \\
$e_{P}$ & 53.3 & 59.4 & 73.5 & 51.3 \\
$r$ & 0.56 & 0.41 & 0.51 & 0.51 \\
\hline
\end{tabular}

Table 2. Mean percentage error $\left(e_{P}\right.$ and $\left.e_{P E}\right)$ and Pearson's coefficient $(r)$ calculated in the validation/prediction period for monthly potential evaporation (PE) series. Values of $r$ in italics are statistically significant at $95 \%$ of confidence level.

\begin{tabular}{lcccccccccccc} 
& Jan & Feb & Mar & Apr & May & Jun & Jul & Aug & Sep & Oct & Nov & Dec \\
$e_{P}$ & 15.7 & 17.1 & 16.0 & 12.7 & 11.9 & 10.7 & 12.7 & 10.2 & 16.2 & 16.5 & 21.8 & 30.8 \\
$e_{P E}$ & 114.6 & 72.4 & 89.9 & 83.6 & 111.1 & 106.9 & 115.3 & 88.0 & 108.5 & 146.1 & 135.4 & 121.3 \\
\hline$r$ & 0.22 & 0.62 & 0.48 & 0.42 & 0.24 & 0.28 & 0.11 & 0.50 & 0.24 & 0.04 & 0.18 & 0.04 \\
\hline
\end{tabular}



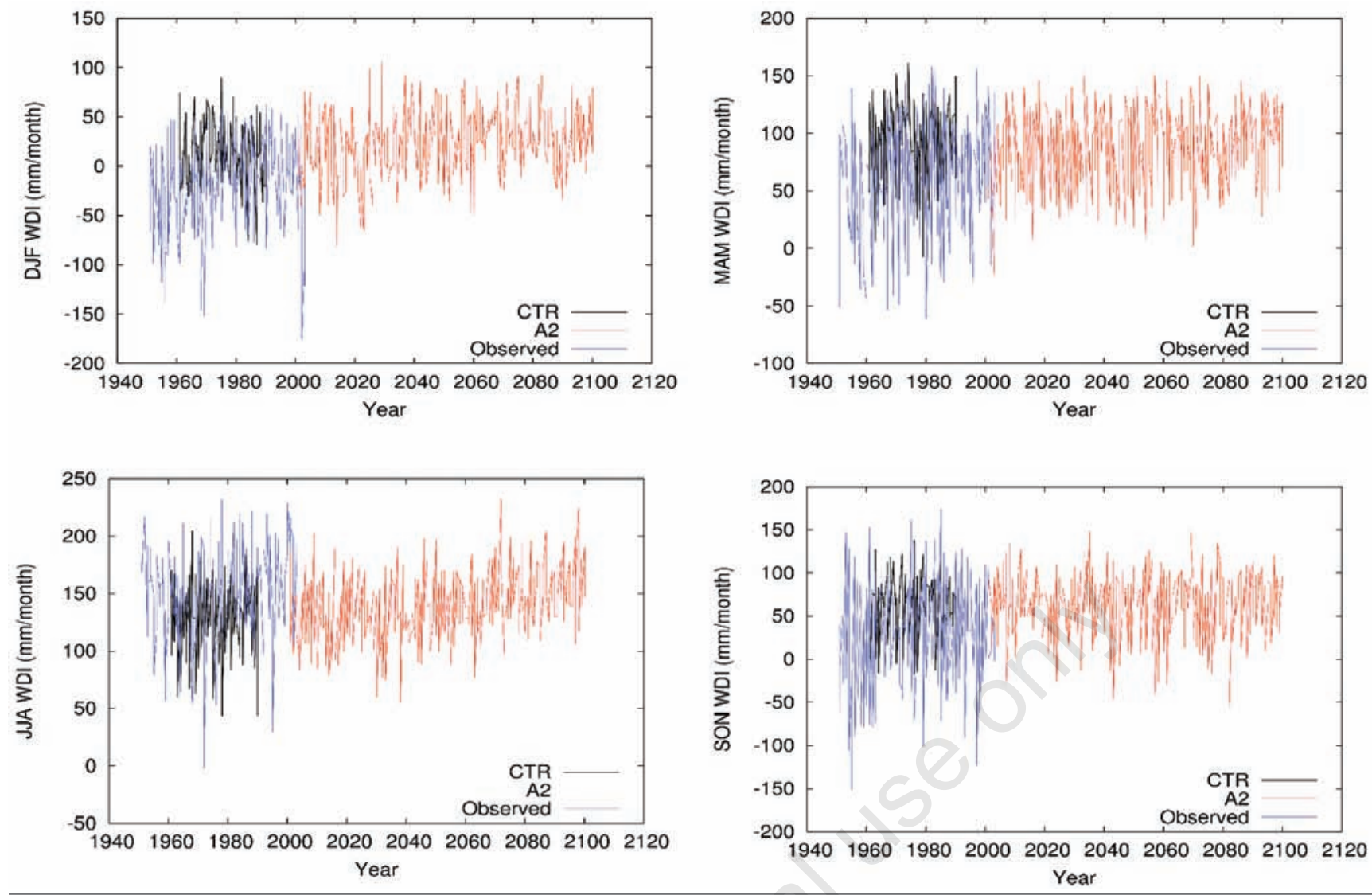

Figure 1. Predicted evolution of water deficit index (WDI) for different seasons. For comparison figures show the observed values and CTR results.

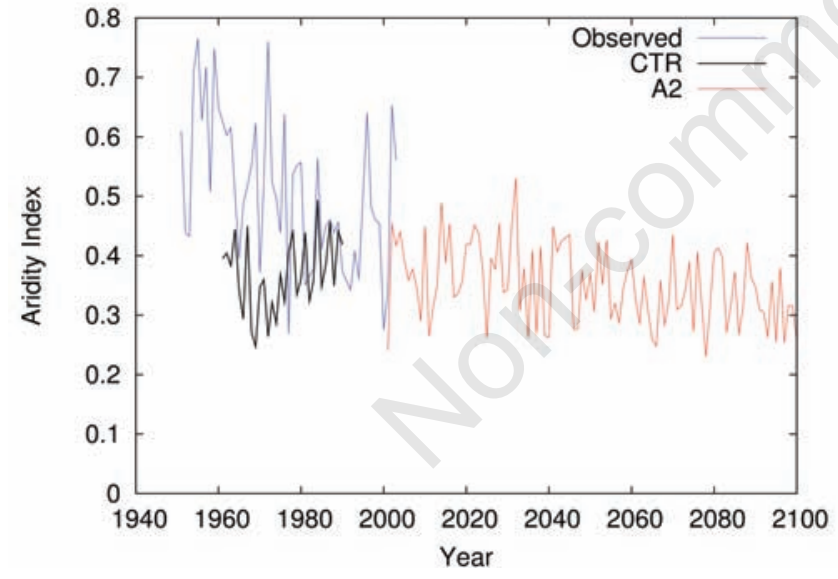

Figure 2. Predicted evolution of aridity index (AI) for the different seasons. For comparison figures show the observed values and the Control Run (CTR) results.

the validation series is in general different from that obtained in the training series. For this reason both error indicators, $e_{P}$ and $\mathrm{e}_{P E}$ should be observed to evaluate the reliability of the technique used. Summarizing, the main issue from the above analysis is that the proposed statistical downscaling has some skills in forecasting the PE, in particular during the spring-summer period, when the crops are usually cultivated and irrigated.

In Figures 1 and 2, we compare the seasonal and annual climatic projections for WDI and AI respectively, together with the observed and
CTR data. It is worth noticing that the agreement found between CTR and observed data can be seen as a measure of the correspondence between the observed and the described climate by the GCM. In order to statistically evaluate the difference between A2 climatic projection and CTR data we divide $\mathrm{A} 2$ projection time series in three thirty years long sub-periods: 2011-2040 (I), 2041-2070 (II) and 2071-2100 (III). Then we perform the non-parametric Mann-Whitney test between the CTR data and the projections related to each three sub-periods. In Table 3 the related results for P, PE, WDI and AI are given. The sign (+ or -) of the test statistics indicates the direction (increase or decrease) of the change.

Concerning PE, the CTR series over-estimates the observed data during winter and spring while under-estimates it during summer (data not shown here). About trends, the Mann-Whitney statistics denote a significant statistical increasing trends during winter and summer relatively to the periods II and III. In these cases, the causes are likely to be attributed to rising in air temperature and to heat waves, particularly during the summer months (Vitale et al., 2010). Moreover a good agreement between CTR and observed data of the variable P can be observed (data not shown here). The negative sign of test statistics (Table 3) seems to indicate a weak decrease in the level of rainfall even if the only significant value is related to the period II. In opposite, a significant increasing trend is predicted for the summer season of periods II and III.

About WDI, the CTR series reproduced reasonably well the observed series, for all seasons (Figure 1). Also in this case, as for PE, GCM data over-estimate the real values during winter and under-estimate it during summer. The Mann-Whitney statistics indicates a relevant increase during winter (it is significant in periods II and III), and summer season even if it becomes significant only in period III. The AI was calcu- 
Table 3. Results of the Mann-Whitney test applied to precipitation, potential evaporation, water deficit index and aridity index predicted series. Statistics refers to the comparison between CTR data and the projections related to periods: 2011-2040 (I), 20412070 (II) and 2071-2100 (III). The sign (+ or -) of the statistics indicates the direction of predicted change. Values in italics are statistically significant at $\mathbf{9 5 \%}$ of confidence level as determined by the Mann-Whitney test.

\begin{tabular}{lccccc} 
Climate variations & Period & DJF & MAM & JJA & SON \\
P (mm/month) & I & -1.82 & +3.26 & +3.81 & -1.38 \\
& II & -9.83 & -0.31 & +9.53 & -5.03 \\
& III & -9.43 & -1.99 & +8.68 & -1.78 \\
PE (mm/day) & I & +0.04 & -0.13 & +0.10 & +0.01 \\
& II & +0.16 & -0.08 & +0.46 & +0.00 \\
& III & +0.23 & -0.10 & +1.02 & -0.02 \\
\hline WDI (mm/month) & I & +3.07 & -7.30 & -0.85 & +1.77 \\
& II & +14.56 & +4.40 & +0.63 & +4.84 \\
& III & +16.33 & -0.96 & +21.88 & +1.10 \\
AI (\%, whole year) & I & & +0.80 & \\
& II & & -2.50 & \\
& III & \multicolumn{5}{c}{-3.60} \\
\end{tabular}

DJF, December-January-February; MAM, March-April-May; JJA, June-July-August; SON, SeptemberOctober-November; $\mathrm{P}$, precipitation; $\mathrm{PE}$, potential evaporation; WDI, water deficit index; $\mathrm{AI}$, aridity index.

lated for the whole year and we observe a non-significant increase in the first period, while in the second period a still non-significant decrease (corresponding to an augmented need of water) is observed. Finally, in the last period a significant decrease of $3.60 \%$ is obtained. In average, the climate results to be $d r y$ before 2000 decreasing up to semi-arid in the last part of the present century.

In addition, in order to determine the magnitude of change, the evaluation of the slope coefficient of a linear function of time was estimated by least squares method. This approach should not be considered as the best way to model the series, but as the simplest and easiest way to interpret the resulting trends.

Concerning the climate projections of WDI at seasonal scale, i) it should increase of about $60 \mathrm{~mm} / \mathrm{season}$ per century during DJF. This value is distributed in an equitable manner (about $20 \mathrm{~mm} / \mathrm{month}$ per century) for each of three months; ii) Results regarding MAM and SON are quite constant and no trends is noticeable; iii) An increase of about $60 \mathrm{~mm} / \mathrm{season}$ is apparent during JJA with a predominant and increasing trend in August (about $40 \mathrm{~mm}$ per century). This result is likely based on one hand to the summer heat waves provided by GCM that affect PE, while on the other to the limit of statistical downscaling to well estimate sudden and intense local rainfall characterized this area during the last decade of August. Concerning the yearly projection of AI; iv) it decreases significantly only in the III period, by showing anyway a constant slowly decrease from the next years until 2100; v) Furthermore, it goes from a mean value of 0.5 (dry land) for the last 20 years to a mean value of $0.3-0.25$ (semi-arid to arid) in the period 2040 2100 , being semi-arid for the next thirty years.

\section{Conclusions}

This study shows a procedure for producing downscaled climatic projections of precipitation, potential evaporation and related water deficit and aridity indexes, starting from the temperature at $1000 \mathrm{hPa}$ (T) and sea level pressure (SLP) of GCM simulations. The downscaling was carried out for the A2 AR4 IPCC emissions scenario.

This study confirms that statistical downscaling techniques are useful tools for the forecast of single agro-climatic variables as $\mathrm{P}$ and $\mathrm{PE}$, providing that the training/calibration period is long enough to well describe the phenomenon complexity. These considerations allow to interpret and take into consideration the climatic projections of WDI and $\mathrm{AI}$, variables useful for irrigation system design and management of lands in the framework of climate change.

From an agronomical point of view, these projections offer more information than those based only on temperature and precipitation, because they help to determine the temporal evolution of the real water requirements in agriculture. This is particularly important when the seasonal precipitation is not sufficient to meet the transpirative plant demand. In particular, the increase in WDI of about $60 \mathrm{~mm} / \mathrm{season}$ per century, during winter and summer seasons, must to be taken into account in water management. For example, for winter wheat cultivated in Mediterranean areas, it could be increase the probability to irrigate during the winter period. This is also due to the typical advance of phenological phases caused by the expected temperature increase. The increase of WDI during the winter period could have a negative impact also for the spring crops due to the low soil water content at sowing time. However, the increase of WDI in summer and in particular in August, could have a lower impact on irrigation management of herbaceous crops, because few species need to be irrigated in the final part of their cycle.

The AI was calculated for the whole year, then it does not show a similar relevant change. Consequently it is not so immediate to achieve an agronomical impact of its changes, but surely it gives an idea about the possibility of aridity risk following climate change. This fact could be useful to eventually address future changing of land purposes and crop species to be cultivated, both at agricultural and forest level (Le Houérou, 1996; Gao and Giorgi, 2008; Seneviratne et al., 2006)

Our results confirm and support the need to adopt strategies of adaptation for the agricultural activities in order to cope with the expected increase of WDI and the decrease of AI, as to optimize the choice of crops/varieties, irrigation method, soil fertilization and soil tillage. To properly face the consequences of climate change in arid and semi-arid regions all these considerations should be conduct in a integrated way.

\section{References}

Aguado E, James EB, 2010. Understanding Weather and Climate. 5th ed., Prentice Hall, Upper Saddle River, NJ, USA.

Ansell TJ, Jones PD, Allan RJ, Lister D, Parker DE, Brunet M, 2006. Daily mean sea level pressure reconstructions for the European North Atlantic region for the period 1850-2003. J. Climate 19:27172742.

Budyko MI, 1974. Climate and life. Academic Press, San Diego, CA, USA.

Castrignanò A, De Benedetto D, Girone G, Guastaferro F, Sollitto D, 2010. Characterization, delineation and visualization of agro- ecozones using multivariate geographical clustering. Ital J Agron 5:121-132.

Davis NE, 1970. Optimum summer index and average potential water deficit. J. Appl. Ecol. 7:229-235.

Deardoff JW, 1977. A parameterization of ground-surface moisture content for use in atmospheric prediction models. J. Appl. Meteor. 16:1182-1185.

Gao X, Giorgi F, 2008. Increased aridity in the Mediterranean region under greenhouse gas forces estimated from high resolution simulations with a regional climate model. Global Planet. Change 62:195-209.

Gerten D, Schaphoff S, Haberlandt U, Lucht W, Sitch S, 2004. Terrestrial vegetation and water balance-hydrological evaluation of a dynamic global vegetation model. J. Hydrol. 286:249-270. 
Hertig E, Jacobeit J, 2008. Assessment of Mediterranean precipitation changes for the 21st century using statistical downscaling techniques. Int. J. Cimatol. 28:1025-1045.

Katerji N, Rana G, 2011. Crop reference evapotranspiration: a discussion of the concept, analysis of the process and validation. Water Resour. Manag. 25:1581-1600.

Le Houérou HN, 1996. Climate change, drought an desertification. J. Arid Env. 34:133-185.

Lionello P, Elvini E, Nizzero A, 2003. A procedure for estimating wind waves and storm-surge climate scenarios in a regional basin: the Adriatic Sea case. Clim. Res. 23:217-231.

Monteith JL, 1965. Evaporation and environment. In: G.E. Fogg (ed.) The state and movement of water in living organism. Soc. Exp. Biol. Symp. 19:205-234.

Neilson R, 1995. A model for predicting continental-scale vegetation distribution and water balance. Ecol. Appl. 5:362-385.

Oldekop EM, 1911. On evaporation from the surface of river basins. Trudy Iurev Observatory, Leningrad, Russia.

Palatella L, Miglietta MM, Paradisi P, Lionello P, 2010. Climate change assessment for Mediterranean agricultural areas by statistical downscaling. Nat. Hazards Earth Syst. Sci. 10:1647-1661.

Penman HL, 1948. Natural evaporation from open water, bare soil and grass. P. Roy. Soc. A Math. Phy. 193:120-146.

Perrier A, 1975a. Etude physique de l'èvapotranspiration dans les conditions naturelles. I. Evaporation et bilan d'ènergie des surface naturelles. [Article in French]. Ann. Agron. 26:1-18.

Perrier A, 1975b. Etude physique de l'èvapotranspiration dans les conditions naturelles. II. Expression et parametres donnant l'èvapotranspiration rèelle d'une surface mince. [Article in French]. Ann. Agron. 26:105-123.

Perrier A, 1975c. Etude physique de l'èvapotranspiration dans les conditions naturelles. III. Evapotranspiration rèelle et potentielle des couverts vègètaux. [Article in French]. Ann. Agron. 26:229-243.

Roeckner, 2005. IPCC DDC AR4 ECHAM5/MPI-OM 20C3m and SRA2 run1. World Data Center for Climate. CERA-DB "EH5_MPI_OM_20C3M_1" and "EH5_MPI_OM_SRA2_1".
Available from: http://cera-www.dkrz.de/WDCC/ ui/Compact.jsp? acronym=EH5_MPI_0M_20C3M_1

Saaroni H, Ziv B, 2000. Summer rain episodes in a Mediterranean climate, the case of Israel: climatological-dynamical analysis. Int. J. Climatol. 20:191-209.

Seneviratne SI, Luthi D, Litschi M, Schär C, 2006. Land-atmosphere coupling and climate change in Europe. Nature 443:205-209.

Tsakiri G, Vangelis H 2005. Establishing a drought index incorporating evapotranspiration. European Water 9/10:3-11.

UN, 1994. United Nations Convention to Combat Desertification in Those Countries Experiencing Serious Drought and/or Desertification, Particularly in Africa. Paris, France.

UNEP, 1992. World Atlas of Desertification. Edward Arnold Ed., London, UK.

Vitale D, Rana G, Soldo P, 2010. Trends and extremes analysis of daily weather data from a site in the Capitanata plain (southern Italy). Ital. J. Agron. 5:133-143.

von Storch H, Zorita E, Cubash U, 1993. Downscaling of global change estimates to regional scales: an application to Iberian rainfall in wintertime. J. Climate 6:1161-1171.

von Storch H, Zwiers FW, 1999. Statistical Analysis in Climate Research. Cambridge University Press, Cambridge, UK.

Wilby RL, Charles SP, Zorita E, Timbal B, Wheton P, Mearns LO, 2004. Guidelines for use of Climate Scenarios Developed from statistical downscaling methods. Available from: http://www.ipcc-data.org/ guidelines/dgm_no2_v1_09_2004.pdf.

Zhang L, Dawes WR, Walker GR, 1999. Predicting the effects of vegetation changes on average catchment water balance. Technical report 99/12, Cooperative research center for Catchment Hydrology; Available from: http://www.catchment.crc.org.au/ pdfs/technical199912.pdf

Zorita E, von Storch H, 1999. The analog method as a simple statistical downscaling technique: comparison with more complicated methods. J. Climate 12:2474-2489. 